\title{
Propagación In Vitro de Platicerium andinum Baker a partir de esporas
}

\section{In vitro propagation of Platicerium andinum Baker from spores}

\author{
Astriht Ruiz Rios ${ }^{1}$, Geyden Díaz Montes² y Astrid Domy Gutiérrez Ruiz² \\ ${ }^{1}$ Universidad Nacional de San Martín - Tarapoto, Jr. Maynas № 177 - Tarapoto \\ ${ }^{2}$ Corporación G y G E.I.R.L., Jr. 02 de Mayo № 340 - Moyobamba
}

DOI: https://doi.org/10.33017/RevECIPeru2015.0007/

\section{Resumen}

Los bosques del departamento de San Martin, hábitat de Platycerium andinum B. viene siendo destruido de manera desmesurada, ocasionado por actividades antropogénicas, como la extracción de madera, incendios forestales, migración y cambio de uso de la tierra, lo que ha conducido a la especie a que actualmente se encuentre en peligro de extinción, sumándose a ello la extracción de la especie por su exuberante belleza para su comercialización como planta ornamental, asimismo a que sus esporas son difíciles de germinar en condiciones naturales. Además, no se cuenta con una metodología para la propagación in vitro de esta especie. La presente investigación tiene como objetivos determinar la concentración adecuada de hipoclorito de sodio para la obtención de esporas de Platycerium andinum B. libre de patógenos para su óptima germinación y evaluar tres medios de cultivo para determinar el medio más adecuado para la propagación de los gametofitos a través de cultivo in vitro. Las esporas fueron obtenidas de frondas fértiles de plantas adultas de Platicerium andinum B. haciendo un raspado de estas. Previa exposición de las esporas a una temperatura de $30{ }^{\circ} \mathrm{C}$ por espacio de 12 horas en estufa, estas fueron desinfectadas en una jeringa de $20 \mathrm{ml}$. en la cámara de flujo laminar con hipoclorito de sodio a tres diferentes concentraciones $\left(T_{1}: 0.5 \%, T_{2}: 1 \%\right.$ y $T_{3}$ : $1.5 \%)$ por un tiempo de 20 minutos y cuatro enjuagues con agua destilada estéril; obteniendo como mejor resultando con el tratamiento $\mathrm{T}_{3}:(1.5 \%)$. La germinación de las esporas fue evaluada a partir de los 10 días, tiempo en el cual comenzaron a germinar y a los 30 días ya se tenía abundante tejido gametofitico; se evaluó a través del Índice de Germinación de las esporas (IG) utilizando la escala de abundancia-cobertura de Braun-Blanquet (Mermoz y Martín, 1993 modificada por Ramírez et al., 2000) llegando a los 60 días a la escala 5 (Cualquier número de gametofitos con cobertura mayor de $75 \%$ ). En cuanto a la determinación del mejor medio de cultivo para la propagación in vitro de gametofitos se trabajó con tres medios $\mathrm{MS}_{\mathrm{B}}\left(\mathrm{T}_{1}, \mathrm{~T}_{2}\right.$ y $\left.\mathrm{T}_{3}\right)$ con aditivos de $0.4 \mathrm{ml}$. de thiamina, 0.5 de ácido nicotínico, 2 gramos de carbón activado y 20 gramos de sacarosa; con $100 \mathrm{ml}$ de agua de coco en $\mathrm{T}_{2}$, y $200 \mathrm{ml}$ en $\mathrm{T}_{3}$, obteniéndose como mejor resultado al tratamiento $\mathrm{T}_{1:}$ ( $\mathrm{M}$ y S Basal, con adición de $0.4 \mathrm{ml}$. de thiamina, 0.5 de ácido nicotínico, 2 gramos de carbón activado y 20 gramos de sacarosa).

Descriptores: Gametofito, haploide, esporas, cultivo in vitro.

\section{Abstract}

Forests department of San Martin, habitat of Platycerium andinum B. is being destroyed disproportionately, caused by anthropogenic activities such as logging, forest fires, migration and changing land use, which has led to the species to which is currently in danger of extinction, adding to it the extraction of the species for its lush beauty for marketing as ornamental plant, also to the spores are difficult to germinate under natural conditions. Also, we do not have a methodology for in vitro propagation of the species. This research aims to determine the appropriate concentration of sodium hypochlorite to obtain spores of Platycerium andinum B., free of pathogens for optimum germination and evaluate three culture media to determine the most suitable 
medium for the propagation of the gametophytes through in vitro culture. The spores were obtained from fertile fronds of adult plants of Platicerium andinum B. making a scraping of these. Prior exposure of spores at a temperature of $30{ }^{\circ} \mathrm{C}$ for 12 hours in an oven, these were disinfected in a $20 \mathrm{ml}$ syringe. In laminar flow chamber with sodium hypochlorite at three different concentrations $\left(T_{1}: 0.5 \%, T_{2}: T_{3} 1 \%: 1.5 \%\right)$ for a time of 20 minutes and four rinses with sterile distilled water; obtaining as being better with the treatment T3 (1.5\%). The spore germination was evaluated after 10 days, at which time began to germinate and after 30 days we had plenty gametophytic tissue; it was evaluated through the germination rate of the spores (IG) using the scale of abundance-coverage Braun-Blanquet (Mermoz and Martin, 1993 as amended by Ramirez et al., 2000) coming to 60 days through 5 scale (Any number of gametophytes more coverage $75 \%$ ). As for determining the best medium for the in vitro propagation of gametophytes we worked with three media MSB $\left(T_{1}, T_{2}\right.$ and $\left.T_{3}\right)$ with additives of $0.4 \mathrm{ml}$. thiamine, 0.5 nicotinic acid, 2 grams of activated carbon and $20 \mathrm{~g}$ of sucrose; with $100 \mathrm{ml}$ of coconut water in $\mathrm{T}_{2}$, and $200 \mathrm{ml}$ in $\mathrm{T}_{3}$, obtaining as best result for $\mathrm{T}_{1}$ ( $\mathrm{M}$ and $\mathrm{S}$ Basal, added $0.4 \mathrm{ml}$ thiamine, 0.5 nicotinic acid, 2 grams of activated carbon and 20 grams of sucrose).

Keywords: Gametophyte, haploid spores, in vitro culture.

\section{Introducción}

Los helechos son plantas muy antiguas, ligadas al principio de la vida sobre la tierra. No producen flores, frutos ni semillas; por lo que su reproducción, fisiología y características intrínsecas los hacen muy diferentes al resto de las plantas y sin embargo poseen un gran atractivo visual que los colocan en un sitial de honor entre las plantas ornamentales [1].

Al no producir semillas su reproducción sexual depende de la producción de esporas (haploides) microscópicas, resistentes y que al germinar en un medio adecuado desarrollan una planta libre haploide denominada gametófito, generadora de gametos masculinos (móviles) y femeninas (sésiles), las cuales al unirse producen la forma conocida del helecho, el esporófito [2].

Platycerium es uno de los pocos géneros de helechos pantropical. Hay seis Especies en África y Madagascar, 8 a 11 en Australia y Asia, y sólo uno en América del Sur tropical, este es $P$. andinum B. [3]. $P$. andinum B. es el helecho epifito más grande de las Américas. Este helecho es la única especie de Platycerium propia del trópico sudamericano y que se encuentra en el Perú en localidades aisladas de San Martin a Puno, con poblaciones asociadas a los boques estacionalmente secos y en rangos de altitud de los 100 a 1100 m. [4]. Según Vail (1984) esta especie es una planta epifita que vive sobre otras plantas pero no es un parasito, no dispone de flores y se reproduce por esporas que son sopladas de un árbol a otro por el viento, una nueva planta comienza a crecer a partir de una espora que se adhiere a una rama o tronco de un árbol [5]; estas se encuentran amenazada dado a la pérdida de su habitad ocasionado principalmente por las actividades antropogénicas, asimismo a que sus esporas son difíciles de germinar en condiciones naturales y por su extracción para la comercialización por su exuberante belleza. Por otro lado no se cuenta con estudios sobre propagación por cultivo in vitro de esta especie lo que es una alternativa productiva que nos permitirá una producción masiva de $P$. andinum $\mathrm{B}$.

El objetivo del presente estudio es determinar la concentración adecuada de hipoclorito de sodio para la obtención de esporas libre de patógenos para su óptima germinación y asimismo obtener el medio de cultivo adecuado para la propagación de los gametofitos a través de cultivo in vitro.

\section{Método Experimental.}

\subsection{Material vegetal}

Se utilizó las frondas fértiles de $P$. andinum $\mathrm{B}$., en cuyo envés se localizan los esporangios conteniendo las esporas, de reciente colecta presentando color madera formida (\#DEB887); según el código hexadecimal de colores (Foto 01).

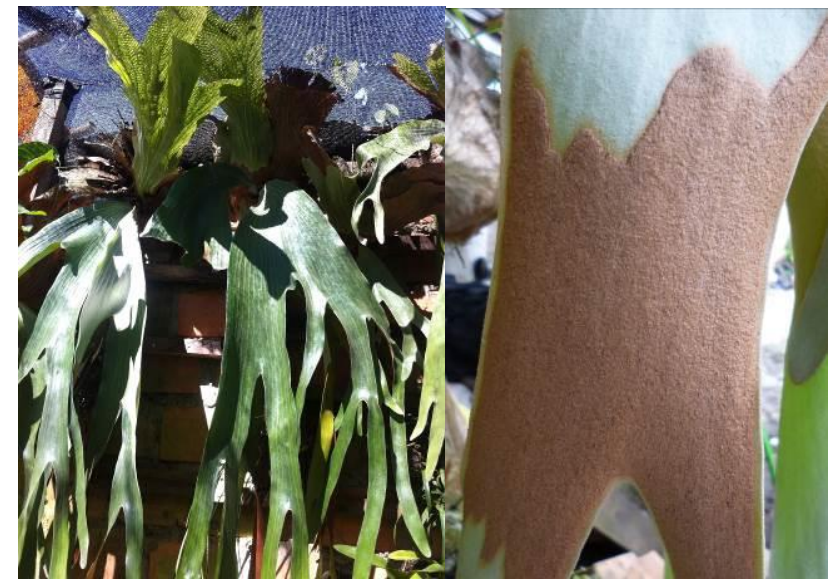

Foto 01: Frontas fértiles de $P$. andinum $B$ conteniendo esporangios. 


\subsection{Metodología para la desinfección y germinación in vitro de esporas}

Se cortaron las frondas que contenían los esporangios, del cual se hizo un raspado muy suavemente con un bisturí sobre un papel von blanco. Las esporas fueron expuestas por un periodo de 12 horas a $30{ }^{\circ} \mathrm{C}$ en estufa para favorecer la dehiscencia de los esporangios. Un gramo de esporas fueron colocadas en una jeringa de $20 \mathrm{ml}$. conteniendo un tapón de algodón hasta 5 centímetro, enseguida se succionó $10 \mathrm{ml}$ de hipoclorito de sodio $(\mathrm{NaClO})$ en tres concentraciones $(0.5,1$ y $1.5 \%)$ por un tiempo de desinfección de 20 minutos. Se hizo 4 enjuagues con agua destilada estéril. Todo este procedimiento se desarrolló en cámara de flujo laminar.

Enseguida se procedió con la siembra colocando cantidades similares de esporas de manera homogénea en un medio de cultivo Básico de Murashige y Skoog (1962) $\mathrm{B}_{\mathrm{MS}}$, con adición de 0.4 $\mathrm{ml}$. de thiamina, 0.5 de ácido nicotínico, 2 gramos de carbón activado y 20 gramos de sacarosa, previa esterilización por autoclavado a 15 libras de presión por 15 minutos, a $121{ }^{\circ} \mathrm{C}$. Las condiciones de desarrollo en cámara fue a fotoperiodo de 16/8 horas (luz/oscuridad), temperatura de $25 \pm 1^{\circ} \mathrm{C}$ y humedad relativa de 90 a $100 \%$.

\subsection{Metodología para la propagación in vitro de gametofitos}

Los gametofitos obtenidos fueron introducidos en medio de cultivo de Murashige y Skoog (1962) con adición de otros reactivos (Tabla 01) previa esterilización por autoclavado a 15 libras de presión por 20 minutos, a $121{ }^{\circ} \mathrm{C}$. Su desarrollo en cámara fue a fotoperiodo de 16/8 horas (luz/oscuridad), temperatura de $24 \pm 1^{\circ} \mathrm{C}$ y humedad relativa de $90 \mathrm{a}$ $100 \%$.

Tabla 01: Medio para el desarrollo de los gametofitos

\begin{tabular}{|l|c|c|c|}
\hline \multirow{2}{*}{ Reactivos } & \multicolumn{4}{|c|}{ Medios de Multiplicación } \\
\cline { 2 - 4 } & $\mathrm{T}_{1}$ & $\mathrm{~T}_{2}$ & $\mathrm{~T}_{3}$ \\
\hline $\begin{array}{l}\text { Macro y micronutriente MS } \\
\text { (Murashige and Skoog) }\end{array}$ & $\mathrm{C}$ & $\mathrm{C}$ & $\mathrm{C}$ \\
\hline Acido nicotínico (mg/L) & 0.5 & 0.5 & 0.5 \\
\hline Thiamina $\mathrm{HCl}(\mathrm{mg} / \mathrm{L})$ & 0.4 & 0.4 & 0.4 \\
\hline Agua de coco (ml/L) & & 100 & 200 \\
\hline Sacarosa g/L & 20 & 20 & 20 \\
\hline
\end{tabular}

\begin{tabular}{|l|c|c|c|}
\hline Carbón activado g/L & 2 & 2 & 2 \\
\hline Agar & 9.5 & 9.5 & 9.5 \\
\hline pH & \multicolumn{3}{|c|}{$5,4-5,6$} \\
\hline
\end{tabular}

3. Resultados y Discusión

\subsection{Desinfección y Germinación in vitro de esporas}

La mejor concentración de hipoclorito de sodio para la desinfección de esporas fue del $1.5 \%$ ya que influencio significativamente sobre el porcentaje de frascos libres de contaminación por patógenos (Grafico 01) y se pudo comprobar que no afecto la germinación de las esporas (Foto 02), a los 10 días se pudo observar que estas comenzaron a germinar y a los 30 días ya se tenía abundante tejido gametofitico con un color verde oscuro y con la presencia de gotas de aceite de color amarillo (Foto 03). El índice de germinación fue de $75 \%$.

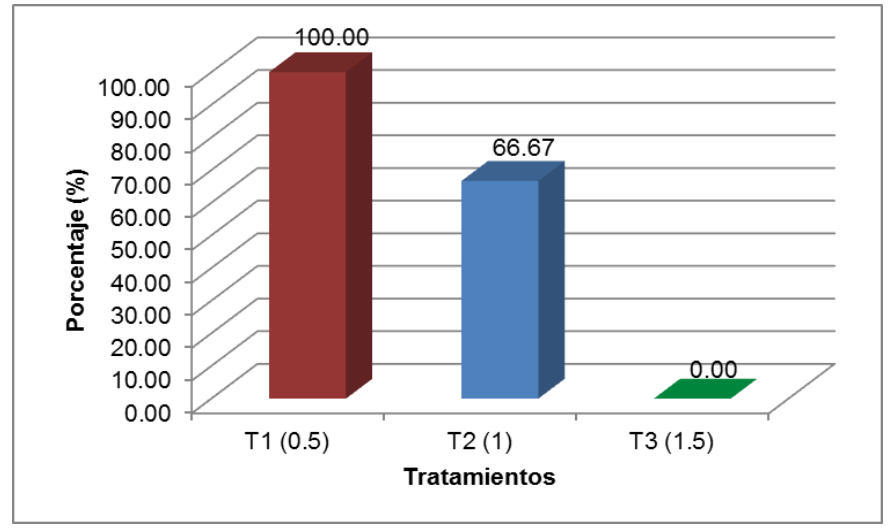

Gráfico 01: Frontas fértiles de $P$. andinum $B$. conteniendo esporangios.

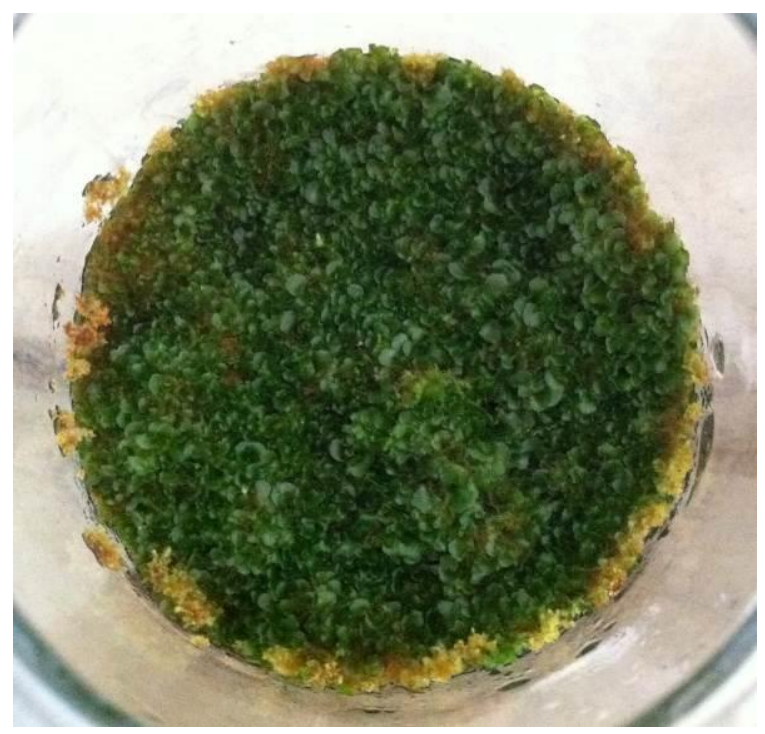

Foto 02: Formación de gametofitos de P. andinum B. 


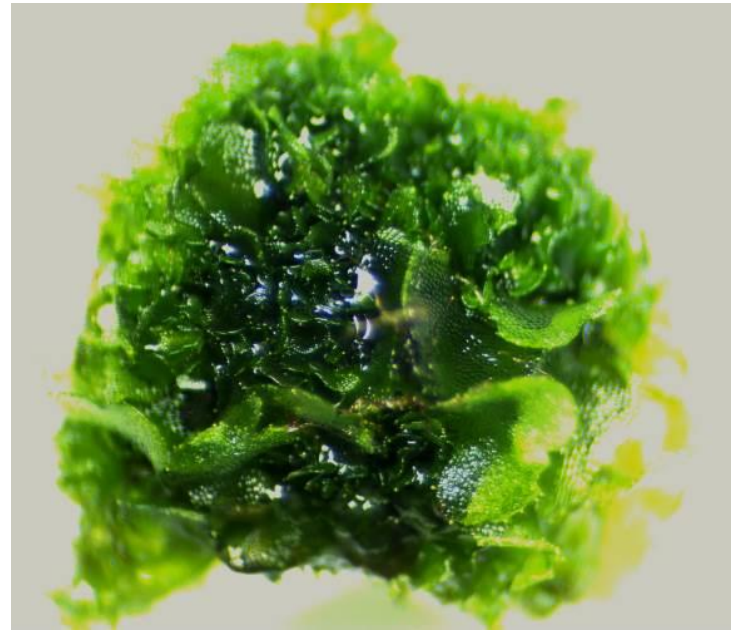

Foto 03: Tejido gametofitico joven de $P$. andinum $B$.

Vásquez et al, (2012), manifiesta que en siete taxas epífitos de Polypodium (Polypodiaceae) las esporas germinaron entre los 6 y los 8 días posteriores a la siembra; en este proceso se observan grandes glóbulos de aceite (gotas lipídicas) de color amarillo en la primera célula protálica y que seguramente participan en la división celular y el crecimiento del gametofito, característica que comparte con muchas otras Polypodiaceae s. str. [6], [7], [8], y [9].

Según Parra, (2013), en el helecho arborescente Cyathea aff. caracasana (KLOTZSCH) DOMIN, la germinación de esporas se presentó entre los 18 y 22 días después de la siembra con un porcentaje del 69\% (IG: 3,75) [10], García, et al., (2013), manifiesta que con los resultados obtenidos en su investigación definió que con el $2 \%$ de hipoclorito de sodio y 15 minutos de exposición se logró disminuir la contaminación microbiana y no se afectó la germinación de las esporas de $C$. bifurcatum, asimismo indica que a los 60 días de estar las esporas dispersas en el medio de cultivo se comenzó a observar su germinación y ya a los 90 días existía abundante tejido gametofítico. La concentración de desinfectante empleada tuvo influencia en la variable de germinación de las esporas [11].

Con 3\% disminuyó el índice de germinación lo que se asemeja a los resultados obtenidos por Evangelista et al. (2001) [12], de similar forma Morales, (2003), manifiesta que en el tratamiento de esporas de Cyathea atrovirens (Cyatheaceae) con $2 \% \mathrm{NaClO}$ se observó un mayor porcentaje de gametofitos cordiformes a los 130 días [13].

En el caso de Pteris inermis (Rosenst.) de la Sota, estudiado mediante técnicas de cultivo in vitro, antes de la siembra de las esporas, se realizó la desinfección del material con hipoclorito de sodio comercial al $5 \% \mathrm{v} / \mathrm{v}$ durante 8 minutos, la germinación de esporas recientemente recolectadas comienza a los 6 días, y a los 27 días las que fueron almacenadas durante un año [14].

Gómez, et al., (2005), manifiesta que para la desinfección de esporas de Platycerium bifurcatum realizó una exposición a luz ultravioleta por 5 minutos, y posteriormente inmersiones de 30 segundos en Etanol, seguido de Vitavax® por 3 minutos y a continuación en Hipoclorito de Sodio al $5,25 \%$ por 5 minutos, posteriormente las esporas fueron separadas de la fronda mediante el uso de una espátula por raspado [1].

Estas últimas fueron desinfectadas nuevamente en un tubo de ensayo con Hipoclorito de Sodio al 2,62\% por 5 minutos. De acuerdo al trabajo desarrollado la desinfección de esporas de $P$. andinum B. no requiere de métodos complejos para lograr una desinfección óptima.

\subsection{Propagación in vitro de gametofitos}

Los gametofitos obtuvieron un mejor desarrollo con el medio de cultivo M y S Basal ( $\left.B_{M S}\right)$, con adición de $0.4 \mathrm{ml}$. de thiamina, 0.5 de ácido nicotínico, 2 gramos de carbón activado, 20 gramos de sacarosa, a los 60 días ya se diferencian perfectamente los gametocitos y entre los 80 y 90 se tiene un prótalo maduro en forma espatulada, con pelos tanto en los bordes como en la superficie, con la presencia de raicillas en forma de barbilla de color marrón (Foto 04), a partir de los 120 días se percibe la formación de esporofitos jóvenes (Foto 05).

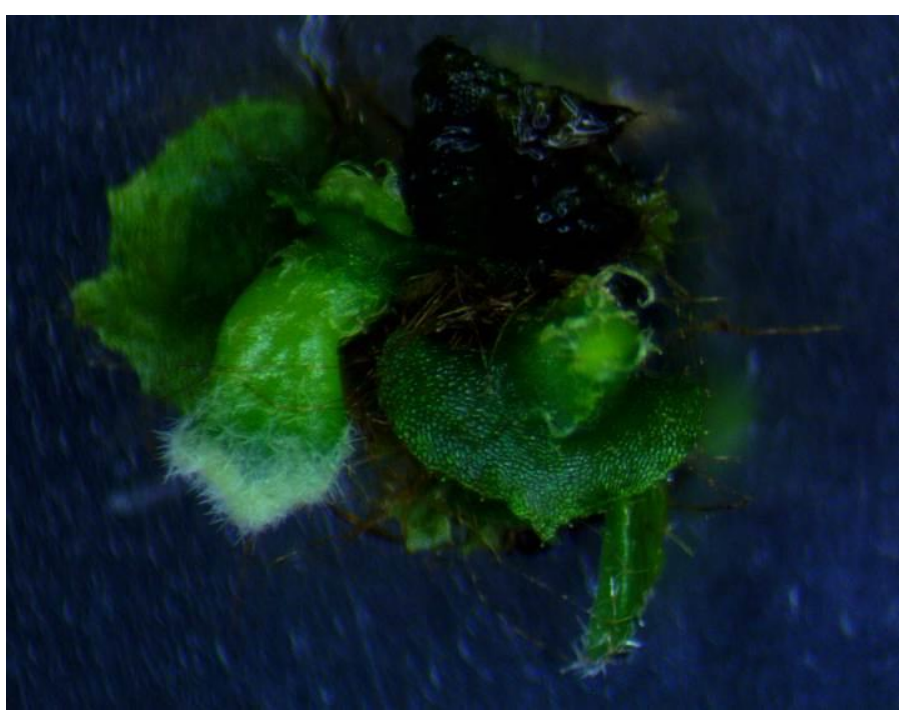

Foto 04: Formación de raicillas de $P$. andinum $B$. 


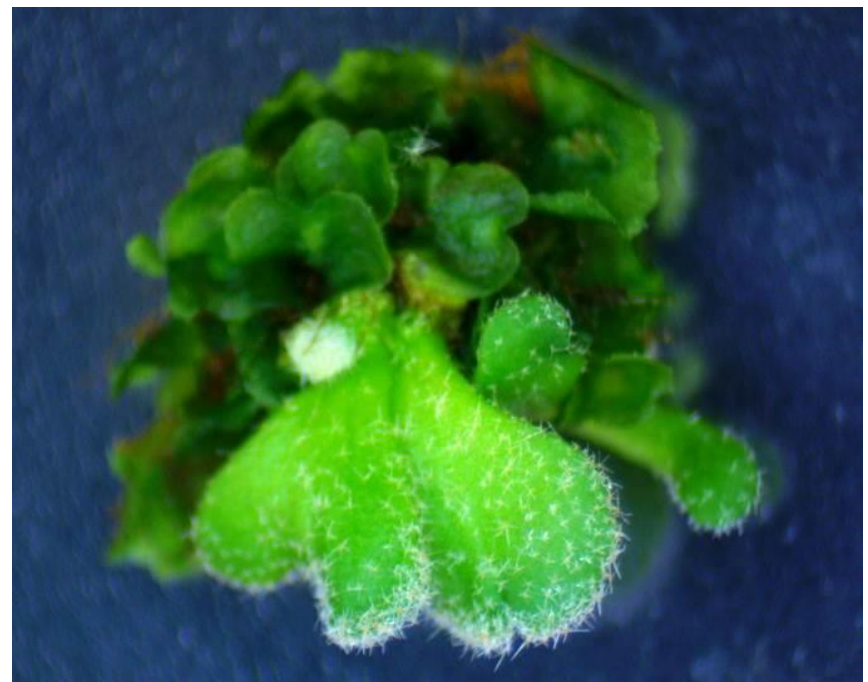

Foto 05: Formación esporofitos jóvenes $P$. andinum $B$.

Los gametofitos de $P$. fraternum (70-75 días), $P$. plebeium (42-46 días), $P$. polypodioides var. aciculare (40-45 días) y $P$. rhodopleuron (60-90 días), son espatulado-cordiformes y ocasionalmente cordiforme, muestran pelos unicelulares secretores y bicelulares no secretores, que se distribuyen tanto en el borde como en la superficie de la lámina (30-37 días). En la parte posterior del gametofito se localizan abundantes rizoides, hialinos o de color pardo claro y sin cloroplastos [6], resultados similares a los obtenidos en la presente investigación.

García, et al., (2013), indica que la mayor multiplicación de los gametofitos se logró con el medio de cultivo que contenía $50 \%$ de las sales $\mathrm{M}$ y S, $1 \mathrm{~m} \mathrm{~g} \mathrm{l}^{-1}$ de tiamina, $2 \%$ de sacarosa en esporas de Platycerium bifurcatum [11], de igual manera Parra, (2013) manifiesta que la germinación in vitro de esporas de Cyathea aff. caracasana se presentó en el tratamiento con el medio de cultivo MS al $50 \%$ sin carbón activado y sacarosa, con el antibiótico rifampicina $(0,02 \mathrm{mg} / \mathrm{L})[10]$.

Según Gómez, (2005), en cultivo in vitro de Platycerium bifurcatum, el medio de cultivo constituido por las sales básicas de Murashige y Skoog fue significativamente mejor para la germinación y sobrevivencia de las esporas que el medio con las sales básicas de Miller y Miller e indistintamente en la literatura científica se ha utilizado para la multiplicación in vitro de plantas de helechos de diferentes géneros el medio de cultivo MS con el 100\% de sales o menos, [15], [16], y [17], lo que nos indica es que las sales de $B_{M S}$ tienen influencia positiva en la propagación del tejido gametofitico [1].

\section{Conclusiones}

La mejor concentración de hipoclorito de sodio para la desinfección de esporas de Platicerium andinum B. fue $T_{3}(1,5 \%)$.

La germinación de las esporas fue evaluada a través del Índice de Germinación de las esporas (IG) utilizando la escala de abundancia-cobertura de Braun-Blanquet [18] llegando a los 60 días a la escala 5 (Cualquier número de gametofitos con cobertura mayor de $75 \%$ ).

El mejor medio de cultivo para la propagación in vitro de gametofitos fue el medio basal $M$ y $S$ (BMS), con adición de $0.4 \mathrm{ml}$. de thiamina, 0.5 de ácido nicotínico, 2 gramos de carbón activado y 20 gramos de sacarosa, lográndose formar esporofitos.

\section{Agradecimientos}

Nuestro sincero agradecimiento a la Universidad Nacional de San Martin - Tarapoto, y a la Empresa Corporación G y G E.I.R.L., a este último en especial por permitirnos ser parte de su proceso de investigación, el mismo que se está desarrollando en marco al Proyecto "Validación del sistema de inmersión temporal para la propagación in vitro de orquídeas, en menor tiempo, con mejor crecimiento y bajo costo, en comparación con los medios de cultivo sólido".

\section{Referencias}

[1] J. Á. Gómez LI. Y Josefina Páez de Cásares. 2005. Tesis: Multiplicación del helecho cacho de venado (Platycerium bifurcatum) in vitro mediante homogeneización de prótalos e in vivo a partir de esporas. Universidad Central de Venezuela. Facultad de Agronomía, pp 96

[2] H. Hartman, D. Kester. Propagación de plantas, principios y prácticas. Tercera reimpresión de la segunda edición. Editorial Continental. (1994) México, pp 759.

[3] B. Pérez, A. Mendoza, S. Espinosa, L. D. Gómez. Gametophyte morphology of Platycerium andinum Baker and Platycerium wandae Racif, Micron 41 (2010), pp 806-813.

[4] B. León, E. Huamán, J. Roque, M. La Torre, y A. Cano. Los Helechos Ornamentales en el Perú. Museo de Historia Natural. Primera Edición. (2012) Perú, pp 50.

[5] R. Vail. Platycerium. Hobbyist's handbook. 
Library of Congress Cataloging in Publication Data.1ra. Edición, pp. 171

[6] N. Vázquez, A. Mendoza, B. Pérez. Morfogénesis de la fase sexual de siete taxa epífitos de Polypodium (Polypodiaceae) de México, Acta Botánica Mexicana, 98 (2012), pp 5-21.

[7] M. R. Ramírez y B. Pérez. Fase gametofítica del helecho Microgramma nítida (Polypodiaceae). Rev. Biol. (1998) Trop. 46(3): pp 587-593.

[8] B. Pérez-García, A. Mendoza, R. Riba y L. D. Gómez. Development of the sexual phase of Pseudocolysis bradeorum (Polypodiaceae). Amer. Fern J. 91 (2001) pp 214-226.

[9] I. Reyes, B. Pérez, A. Mendoza. Morfogénesis de los gametofitos de especies mexicanas de Pleopeltis (Polypodiaceae, subfamilia Pleopeltoideae). Rev. Biol. Trop. 51(2): (2003), pp 321-332.

[10] E. X. Narváez-Parra, J. H. Jerez, J. E. Mantilla. Etapas de desarrollo in vitro del gametofito del helecho arborescente Cyathea aff. caracasana (KLOTZSCH). 120 (2013), pp 74-84

[11] L. R. García, D. Torres, C. Romero. Regeneración de esporofitos de Platycerium bifurcatum (Cav.) C.Chr. a partir de esporas germinadas in vitro, Biotecnología Vegetal 13(2013), pp 99 - 105.

[12] S. Evangelista, S. Escobar, G. Trejo, A. Jiménez. Propagación in vitro de Platycerium bifurcatum. Memorias del IX Congreso Nacional de Biotecnología y Bioingeniería, XIII Congreso Nacional de Ingeniería Bioquímica y II Congreso Internacional de Ingeniería Bioquímica. 2001. Veracruz. México

[13] C. Morales, S. Montes, V. Paneque. Corbera, J. Aclimatación de vitroplantas de helechos a través del cultivo in vitro de esporas utilizando diferentes sustratos formados a partir de distintos abonos orgánicos, Cultivos Tropicales, 24(2003), pp 29-31.

[14] M. E. Tanco, O. G. Martínez y M. L. Bonomo. Germinación y morfogénesis gametofitica de Pterisinermis (rosenst.) de la Sota, Gayana Bot. 66(1): (2009), pp 10-17.

[15] S. Juntadach, Studies on spore culture of fern (Platycerium coronarium and Asplenium nidus) in agar medium. Sonklana Karin Journal of Science and Technology 18(3): (1996), pp 275-286.

[16] J. Cox, P. Bhatia, N. Ashwath. In vitro spore germination of the fern Schizaea dichotoma. Scientia Horticulturae 97: (2003), pp 369-378.

[17] H. Fernández, M. A. Revilla. In vitro culture of ornamental ferns. Plant Cell Tissue and Organ Culture 73: (2003), pp 1-13.

[18] M. R. Ramírez, G. B. Pérez, R. Riba El suelo, un banco natural de esporas y helechos. Contacto S 36: (2000), pp 15-18

E-mail:thirtsa_@hotmail.com, gedimo10@hotmail.com,y astridomy@gmail.com 